\title{
Cartesian epistemology: an introduction
}

\author{
Jean-Baptiste Rauzy ${ }^{1}$. Stefano Cossara ${ }^{2}$. \\ Xiaoxing Zhang ${ }^{1}$
}

Descartes' legacy is crucial in contemporary epistemology. Most of our discussions of knowledge and justification are to a large extent shaped by the issues that Descartes has raised. Descartes' epistemic project, after centuries of criticism, has remained inspirational and still attracts philosophers that interpret and defend its doctrines. As a result, however, "Cartesian epistemology" is becoming burdened with ambiguities. Understood in the most general sense, the term covers those of our discussions in epistemology that descend from Descartes' general framework. More often, the expression "Cartesian epistemology" is used in a more specific sense: it labels a group of epistemological theses that are typically ascribed to Descartes based on a prima facie grasp of his texts, e.g., that introspection can be infallible and that one can secure solid foundations for knowledge. While these theses can in some way be traced back to Descartes' ideas, the way they are currently developed and refined is affected by the dialectical structure of the contemporary debate, where broadly construed "Cartesian" views are customarily opposed to theses such as externalism or coherentism. This development is not constrained by exegetical concerns relative to Descartes' original positions, and as consequence the content of "Cartesian epistemology" tends to blur as the debate evolves: in some cases it is even dubious whether and to what extent positions that are labeled "Cartesian" are actually informed by Descartes' original views.

\footnotetext{
$\bowtie \quad$ Jean-Baptiste Rauzy

jean-baptiste.rauzy@paris-sorbonne.fr

Stefano Cossara

stefano.cossara@unipd.it

Xiaoxing Zhang

zhang@phare.normalesup.org

1 Philosophy Department, Paris-Sorbonne University, 28 Rue Serpente, 75006 Paris, France

2 Department of General Psychology, University of Padova, Via Venezia 8, 35131 Padua, Italy
} 
This special issue was conceived during the conference "Cartesian Epistemology," co-organized by Sciences, Normes, Décision and the Centre d'Études Cartésiennes at Paris-Sorbonne University in 2015. The purpose of the conference, and of this special issue, is to fill this gap in the contemporary debate by bringing to light "Cartesian epistemology" as a precise and consistent epistemological position, one that is at the same time faithful to the details of Descartes' original texts and defendable within the contemporary philosophical debate. In other words, our goal is to bring Descartes back to the centre of the epistemological scenario, by drawing on the details of his texts in order to outline the position that he would actually defend within the current debate. While a complete and satisfactory development of this more ambitious version of Cartesian epistemology is unsurprisingly yet to take shape, the dialogue between epistemologists and Cartesian scholars has so far proven illuminating. Hopefully, this special issue will provide an initial idea of what Descartes' views, faithfully interpreted, can still offer to contemporary epistemology.

Descartes is typically recognized as an internalist foundationalist who thinks that some of our foundational cognitions - clear and distinct perceptions - are infallible. The foundationalist and the infallibility theses tend to be confused in Descartes' texts where he writes about secure foundations of knowledge. Richard Fumerton, in his contribution "Cartesian epistemology and infallible justification," argues that the search for foundational-noninferential justification does not motivate the infallibility thesis. He then tries to show that acquaintance theory is better placed than Descartes' original project to identify the best epistemic justification available.

In "The redundancy problem: from knowledge-infallibilism to knowledge minimalism," Stephen Hetherington rejects knowledge-infallibilism, another thesis normally ascribed to Descartes. Knowledge-infallibilism is motivated by the idea that infallible justification is more conducive to truth than fallible justification. This can be accepted when we consider their "active link" to truth. Static justificatory links, instead, suffer from a redundancy problem: in any possible world, an infallibly justified true belief and a fallibly justified true belief are both true. Hetherington opts for knowledgeminimalism. On this view, knowledge is just true belief; while justification retains its epistemic value, it is no longer constitutive of knowing.

Although most recognize the skeptical force of the Evil Demon argument, there is no agreement on how to understand the argument. Jean-Baptiste Guillon proposes a new reconstruction of the Evil Demon argument in "The Evil Demon argument as based on closure plus meta-coherence." According to Guillon, the Evil Demon skeptical argument should be construed as combining two epistemic principles: closure of justification and meta-coherence. This reconstruction, Guillon argues, better captures the intuition behind the skeptical scenario and is dialectically stronger than previous reconstructions.

Contextualism has been an attractive solution to skepticism; it works fine when the latter is regarded as a paradox involving closure principles. In his "Contextualism and radical skepticism," Duncan Pritchard argues that contextualism fails once we formulate skepticism in terms of underdetermination. Pritchard appeals to epistemic disjunctivism in reply to the underdetermination-based skeptical problem, and presents an independent Wittgensteinian solution to closure-based skepticism. Instead 
of reconstructing the strongest version of skepticism as Guillon does, Pritchard thus understands skepticism as based on two different sources.

The standard narrative of the history of mathematics portrays Descartes' intellectualism as initiating a formal approach to mathematics that assigns no significant role to imagination. David Rabouin argues against this picture in "Logic of imagination. Echoes of Cartesian epistemology in contemporary philosophy of mathematics and beyond." Based on Regulae ad directionem ingenii and other texts by Descartes, Rabouin traces Descartes' work back to a more ancient tradition, typically represented by Proclus, in which imagination is essential for mathematical reasoning.

Although imagination could reveal mathematical truths, Descartes does not heavily rely on it in metaphysics. Conceiving, instead, is the primary tool Descartes employs for drawing metaphysical conclusions. In "Conceivability, inconceivability and Cartesian modal epistemology," Pierre Saint-Germier explores Descartes' notion of conceivability and the way it is connected to metaphysical possibility. Saint-Germier examines in particular a tension between two theses of possibility for Descartes: first, (in)conceivability implies (im)possibility; second, everything is possible by God's omnipotence. Actually, if everything is possible, it would be vacuously true that conceivability implies possibility, and nothing would imply impossibility. Saint-Germier argues that the tension can be solved by recognizing two modalities within Descartes' texts, one related to God's infinite power, the other to the conceivability for finite creatures.

Acknowledgements We would like to thank Giacomo Ganassini for comments on previous versions of this introduction. 